Georgia State University

ScholarWorks @ Georgia State University

7-19-2021

\title{
Housing Vacancy and Hypervacant Neighborhoods: Uneven Recovery after the U.S. Foreclosure Crisis
}

\author{
Austin Harrison \\ Georgia State University, atharrisonllc@gmail.com \\ Dan Immergluck \\ Andrew Young School of Policy Studies, dimmergluck@gsu.edu
}

Follow this and additional works at: https://scholarworks.gsu.edu/urban_studies_institute

Part of the Urban Studies and Planning Commons

\section{Recommended Citation}

Austin Harrison \& Dan Immergluck (2021) Housing vacancy and hypervacant neighborhoods: Uneven recovery after the U.S. foreclosure crisis, Journal of Urban Affairs, DOI: 10.1080/07352166.2021.1945930

This Article is brought to you for free and open access by the Urban Studies Institute at ScholarWorks @ Georgia State University. It has been accepted for inclusion in USI Publications by an authorized administrator of ScholarWorks @ Georgia State University. For more information, please contact scholarworks@gsu.edu. 
Housing Vacancy and Hypervacant Neighborhoods:

Uneven Recovery after the US Foreclosure Crisis

Austin Harrison

and

Dan Immergluck

Forthcoming,

Journal of Urban Affairs

May 21, 2021 


\section{Introduction}

Housing vacancy, especially spatially concentrated longer-term vacancy, has been viewed as a problem in U.S. cities since at least the second half of the twentieth century (Bradbury et al., 1982; Grigsby et al., 1987; Newman et al., 2016; Sternlieb et al., 1974). Starting with postwar suburbanization, and especially from 1980 onward, the number of empty houses in the U.S. rose to substantially higher levels, especially in America's older post-industrial central cities. Beginning especially in the 1990s, urban scholars began focusing more on how many vacant houses there were, where they were located, and what to do in neighborhoods with high concentrations of empty homes (Accordino \& Johnson, 2000; Cohen, 2001; Goetz et al., 1998, and Mallach, 2006). Following the foreclosure crisis beginning in 2007, the vacant home conversation became central to the American housing and community development policy conversation, including the creation of the Neighborhood Stabilization Programs beginning in 2008 (Alexander and Powell, 2011; Immergluck, 2015; Schilling and Logan, 2008). Today, severe levels of vacancy tend to be concentrated in higher-poverty communities of color, especially in Black neighborhoods. Therefore, those seeking to address housing and spatial justice, community development, and the racial wealth gap should pay close attention to this problem.

This paper looks at changes in vacancy during the broader housing recovery since the foreclosure crisis, and particularly the levels of very high and extreme levels of neighborhood vacancy, what we call "hypervacancy," over the 2012 to 2019 period. [We discuss hypervacancy in more detail below, but our definition of hypervacant tracts includes those where long-term vacant units (those vacant for more than six months) are more than 8 percent of residential units; 
these tracts represent approximately the top decile of vacant tracts in 2012 across the 200 largest metropolitan areas.]

We examine neighborhood-level vacancy trends from 2012 to 2019 in the largest 200 metropolitan areas in the U.S. and pay particular attention to two regions, the Rustbelt and Sunbelt. ${ }^{i}$ These two regions were both hit hard by the foreclosure crisis and many - but not all -metros in both regions had high vacancy rates and significant hypervacancy before the national housing market recovery began during 2012 (Hollander, 2011; Mallach, 2018a). There are substantial differences between these two regions in terms of their industrial and post-industrial histories, their longer-term population trends, regional economic divergence, metropolitan growth patterns, and many others. These differences led some scholars to suggest that the Sunbelt would be substantially more resilient to economic and housing market shocks than the Rustbelt (Mallach, 2018a, Mallach, 2018b; Pendall et al., 2015). Pendall et al. (2015), for example, forecasted that Southern and Western metros, many of which are in the Sunbelt, will tend to grow after 2010, while Midwestern and Northern metros, most of which are in the Rustbelt, would shrink. However, many Sunbelt metros were heavily impacted by the subprime mortgage crisis, resulting in increased vacancy during the years leading up to our study period, specifically 2008 to 2011 (Hollander, 2011).

Moreover, the intra-metropolitan housing market dynamics also showcase meaningful regional differences, especially as it relates to the conversion of single-family owner dwellings to rentals. Such high rates of conversions are spatially targeted in ways that have market implications which could be preventing some homes from becoming vacant in the Sunbelt, while rental conversions are less concentrated in the Rustbelt (Immergluck, 2018). Another process contributing to differing intra-metropolitan vacancy patterns is the recent expansion of "ghost 
dwellings" or vacant homes not on the market but also not completely forgotten about or derelict. Recent evidence from the largest 50 cities shows that large Sunbelt cities like Miami, Austin, and Atlanta, are seeing some of the highest concentrations of "ghost dwellings" in the country. For this research, we focus on properties that are likely abandoned or long-term vacant but the existence of ghost dwellings and rental conversions at higher rates in the Sunbelt than the Rustbelt may play some role as well in determining vacancy rates (Wegmann, 2020).

This paper seeks to examine the differences in the levels of vacancy and, especially, hypervacancy in neighborhoods in larger metropolitan areas in these two regions. It also measures changes in vacancy levels and hypervacancy from 2012 to 2019, during a long period of national housing market recovery.

We pose the following research questions. 1) How persistent, or stubborn, was the presence of hypervacant neighborhoods in larger metropolitan areas during the national housing market recovery? 2) How did this differ between the Rustbelt and the Sunbelt? Some literature predicted that we would see greater declines in hypervacant neighborhoods (Mallach, 2018a; Pendall et al. 2015). But others have argued that Sunbelt vacancy might also be more stubborn than that (Hollander, 2011). 3) What are the racial and economic characteristics of neighborhoods associated with hypervacancy? 4) Is there something special about the context of these two regions, above and beyond their metropolitan growth dynamics, that affected their level of hypervacancy at the end of the study period (2019)? 5) Finally, after controlling for metropolitan growth and economic conditions, what neighborhood characteristics are associated with hypervacancy at the end of the long seven-year recovery? Based on previous literature and evidence, we expect hypervacancy to persist to a certain extent in both regions, despite regional narratives situating the Sunbelt recovery as more robust (Pendall et al, 2015; Hollander, 2011). 
Moreover, we anticipate that metropolitan housing market conditions, and not some larger regional setting, will be a better predictor of neighborhood hypervacancy patterns.

This paper is the first that we are aware of to track changes in neighborhood housing vacancy and hypervacancy across the US from the end of the foreclosure crisis through the later years of the 2010s, a lengthy period of national recovery and housing value appreciation. This recovery began in 2012 (Immergluck, 2016) and has continued through at least 2020. We obtained data covering the period from the first quarter of 2012 through the first quarter of 2019, the latest quarter for which data were available. Only two prior national studies have looked at vacancy trends rigorously after the crisis, but they both only look at brief periods, ending in 2014, when the recovery had not gotten up a full head of steam (Immergluck, 2016; Wang and Immergluck, 2019). By looking at a substantially longer period, we examine whether a much longer and stronger recovery may have "pulled up" many hypervacant neighborhoods to higher levels of occupancy. Also, critically, these two earlier two studies do not focus on, or explicitly measure, hypervacancy, the sort of severe vacancy that is likely to create the greatest challenges for cities (Mallach, 2018a).

We begin by briefly explaining why scholars, policymakers, and local communities care about long-term vacant housing. We then review some of the key, relevant literature on housing vacancy in the U.S. context. We do not attempt to review the entire, quite large scholarship on housing vacancy. Rather, we focus on the literature that provides important context for this study both conceptually and empirically. After this, we proceed with our empirical analysis which is composed of three primary exercises. First, we employ cross-tabulations and comparisons over time to describe changes in neighborhood-level vacancy, including hypervacancy, from 2012 to 2019. We do this for the 200 largest metropolitan areas in the U.S. and disaggregate these metros 
by a cost-growth typology and by region (Sunbelt, Rustbelt, other). Next, we examine bivariate associations between changes in vacancy and the race and poverty level of the neighborhood. Finally, we estimate a logistic, multivariate regression that predicts whether a neighborhood (census tract) ends up being hypervacant in 2019 to help us understand which initial characteristics and metropolitan trajectories are associated with hypervacancy.

\section{Why Do We Care About Vacant Housing?}

Vacant and physically distressed housing poses several challenges for local communities. Contemporary analyses of the impact of vacant housing have generally fallen into three areas: crime, health, and surrounding property values. Cui and Walsh (2016) found that vacant, foreclosed homes lead to increases in crime. In Philadelphia, Branas et al. (2012) estimate that an 18 percent increase in the risk of an assault near vacant properties. Moyer et al. (2019) conducted a randomized controlled trial and concluded that reducing vacancy significantly reduced gun violence. In Detroit, Raleigh and Galster (2015) found an association between vacant properties and various types of crime.

Vacant housing is also associated with worse health outcomes for neighborhood residents. Sampson et al. (2017) identified a relationship between abandoned parcels and negative health impacts in Detroit. In Memphis, Shin and Shaban-Nejad (2018) found a statistically significant positive relationship between "blight prevalence" and childhood asthma after controlling for other factors. Wang and Immergluck (2018) conducted a study of the largest fifty U.S. metropolitan areas and found that vacancies of 3 years or more had a significant relationship with health outcomes. 
There is also some literature on the impact of vacant homes on surrounding property values. Han (2014), for example, found that the longer a property sits empty, the greater its negative impact on home values. In Cleveland, Whitaker and Fitzpatrick (2013) examined vacancy, property tax delinquency, and foreclosures separately and estimated that such properties reduce nearby property values by 1 to 2.7 percent.

\section{Key Literature on Housing Vacancy in the U.S.}

The scholarship on housing vacancy in the U.S. is large and dates back at least to the 1970s. This is no coincidence because postwar urban decline accelerated in the 1960s and early 1970s in the wake of urban unrest, white flight, and predatory financial practices such as contract-for-deed home selling and the Federal Housing Administration's (FHA) 235 scandal (Bradbury et al., 1982; Kerner Commission Report, 1968; Satter, 2010; Sternlieb et al., 1974; Taylor, 2019). As metropolitan sprawl persisted in the latter half of the twentieth century, supported by FHA loan programs, federally funded expressways, and other private and publicsector forces, housing investment in many central cities declined, at least investment that was not predatory or extractive (Galster, 2012; Dreier et al., 2014).

The more contemporary literature on housing vacancy in the US often focuses on what has been called "shrinking" or "legacy cities," especially those in the Rustbelt. These are cities with industrial pasts that suffered under deindustrialization while still facing continuing sprawl. As their regional economies and population stagnated or declined, and decentralization continued, many central city neighborhoods in these metros experienced increased housing vacancy (Galster, 2012; Hackworth, 2019; Mallach, 2006). 
The latest stage of literature on housing vacancy often focuses on vacancy patterns during and following the U.S. foreclosure crisis and the Great Recession. The foreclosure crisis accelerated and concentrated vacancy, particularly in Black neighborhoods hit hard by foreclosures (Immergluck, 2009b; Mallach, 2018a; Mallach, 2018b). Some of this work also focused on cities outside the Rustbelt, especially those in the Sunbelt, where massive increases in foreclosures triggered the national foreclosure crisis. It was large metropolitan areas in the "sand states" of Florida, Arizona, Nevada, and California, that transformed what had been somewhat isolated increases in foreclosures into a national crisis (Immergluck, 2009a). Among this literature is that of Hollander (2011), who argued in his Sunburnt Cities that the boom-bust experience in many Sunbelt cities left a large amount of vacant housing in its wake that could persist without major policy and planning interventions.

To understand the factors associated with neighborhood hypervacancy, we start with urban economic theory, which suggests that when a metropolitan area's population declines and housing demand (and prices) fall, that the supply of housing may not fall as quickly, resulting in surplus inventory and vacancy (Glaeser and Gyouko, 2005). Therefore, changes in metropolitan economies and population growth may be important drivers of metropolitan vacancy, which in turn will affect at least average levels of neighborhood vacancy. However, given the literature on the unevenness of housing markets within metropolitan areas, and the forces at play, including discrimination such as racial steering, subprime mortgage lending, and uneven public investment, we also expect neighborhood housing and demographic characteristics to be associated with neighborhood vacancy rates (Hackworth, 2019; Immergluck, 2009a; KorverGlenn, 2018; Taylor, 2019). 
Some recent research on housing vacancy and abandonment attempts to explain or predict the neighborhood-level geography and concentrations of housing vacancy. Morckel (2013) uses a combination of data from the American Community Survey together with locally available data on tax delinquency and mortgage foreclosures in two Ohio cities. She draws on the literature on urban decline to include the neighborhood unemployment rate, the race of residents, the age of housing units, home value, education level, and the proportion of residents over 65 years old. ${ }^{\text {ii }}$ Such localized studies tend to use similar variables constructed from a mix of data from the US Census Bureau and local administrative data sets (see also, e.g., Hillier et al., 2003). One limitation of such studies is that some of the data they use is not readily available, especially in a consistent form, across many different metropolitan areas or cities.

Molloy (2016) was one of the first to use United State Postal Service (USPS) vacancy data to describe long-term vacancy patterns across the U.S. She found that, as of 2013, vacancies lasting over a year were at least one standard deviation higher than the national average in 13 percent of all tracts, and those tracts comprise 39 percent of all the country's longterm vacant units. She also found that these tracts were located not only in distressed inner-city or inner-ring suburban neighborhoods but also in hotter markets. Immergluck (2016) also used USPS data and found that during the 2011 to 2014 period, cities with high poverty rates and lower than average median household incomes saw sustained high rates of long-term vacancy. Because we might expect metropolitan forces, including population and housing price dynamics, to affect vacancy trends, it is helpful to examine such trends across different metropolitan areas or types of metropolitan areas. Mallach (2018a), for example, describes national vacancy trends across four types of cities: magnet cities, Sunbelt cities, large legacy cities, and small legacy cities. He finds that vacancy rates in legacy cities have remained 
substantially higher than that of Sunbelt and magnet cities, with both types of cities having generally experienced the benefits of the national housing market recovery (Mallach, 2018a). This contrasts with the earlier suggestion by Hollander (2011) that Sunbelt cities might suffer long-term vacancy from the housing bust. Our effort here is to examine rigorously the difference in vacancy and hypervacancy trends between Rustbelt and Sunbelt metropolitan areas and their neighborhoods. We do not adopt Mallach's typology, which is based on cities and not metropolitan areas, but instead combine a broad regional classification (Rustbelt, Sunbelt, other) together with a categorization of metros based on housing cost level and growth trajectory.

Our approach to creating a metropolitan typology most resembles, but is distinct from, one used by Wang and Immergluck (2019). They created a metro typology for their study of long-term vacancy trends at the very beginning of the recovery (from 2011 to 2014) to classify the 50 largest metropolitan areas. They classified these metros using cluster analysis with four variables: population growth, growth in the gross domestic product (GDP) from 2005 to 2014, changes in home values, and population growth. Our typology differs from this approach in two fundamental ways. Because we are examining a much larger set of metros, the 200 largest, with a greater amount of heterogeneity, we first distinguish between high- and low-cost metropolitan areas by using their median home values. We identified $\$ 200,000$ as the boundary between lowand high-cost metros. This is roughly equal to the average among the median home values for the 200 metropolitan areas.

The other fundamental difference between our metropolitan classification (described in the next section) and that of Wang and Immergluck (2019) is that we do not use cluster analysis. ${ }^{\text {iii }}$ Instead, we used a more straightforward method of categorizing low- and high-cost metros using two additional variables, population growth, and housing price growth. Population 
growth is perhaps the most straightforward measure of housing market demand. Housing price growth (or decline) is a function of demand relative to the ability to add supply to meet demand. The next section describes our metropolitan typology in more detail.

\section{Data and Methods}

To address the research questions, we proceed as follows. We first describe how we cleaned and organized the USPS data on vacant housing units obtained from the U.S. Department of Housing and Urban Development (HUD). We examine trends across five levels of neighborhood long-term vacancy (vacant continuously for six months or more), ranging from "low" to "extreme." from 2012 to 2019, and break these out for the Sunbelt and Rustbelt. The two highest levels of vacancy, "very high" and "extreme" are, together, considered "hypervacant." We then create a metropolitan-level housing market typology using data on population growth, medium home values, and change in the Federal Housing Finance Agency (FHFA) Housing Price Index (HPI) from 2011 to 2018. The typology includes two levels of median home value, using the American Community Survey, and three levels of growth (using changes in population and the FHFA HPI). We use this typology to compare neighborhood vacancy trends in low-cost, low-growth metropolitan areas, including those in the Sunbelt and the Rustbelt.

Following this, we examine the racial and poverty compositions of tracts at different vacancy levels. Finally, we utilize a logistic regression to identify metropolitan- and neighborhood-level conditions that are associated with a neighborhood ending up in the hypervacant category (a vacancy rate of 8 percent or higher) in 2019.

We begin with USPS data on housing units aggregated to the census tract level by HUD. Postal workers for the USPS record addresses in their service area that show visible external 
signs of vacancy (i.e. mail piling up, lights always off, etc.) into their internal data reporting system. Then, USPS aggregates such data and shares it with third-party entities like HUD. The property is listed as vacant until reported otherwise, so we can track length of vacancy. We exclude short-term vacant addresses (those vacant for less than 6 months) because those will include many for-sale units, for-rent units, and are of less concern here. ${ }^{\text {iv }}$ Using the first quarter of 2012 and 2019 controls for seasonality issues and will exclude most properties vacant for just the winter months.

We restricted our analysis to all residential addresses, which include those in single and multifamily properties. "No-stats" are addresses that range from under construction to completion and it is very difficult to determine which no-stats resemble long-term vacant units. The no-stat data are considered unreliable (HUD Frequently Asked Questions, 2018). Therefore, the second step to data cleaning included removing no-stats from the calculation of the vacancy rate, as recommended by HUD (that is, they were not included in either the numerator or the denominator of the rate calculation). In the third step, we summed all vacant address totals at the tract level for each category from "Vacant 6 Mos. to 12 Mos. Count - Residential" and up to "Vacant 36 Mos. or Longer Count - Residential". This total was divided by the total number of residential addresses, again excluding "no stats". This gives us a long-term vacancy rate at the tract level for both observation periods, Q1 2012 and Q1 2019.

As is the case with any administrative dataset, the USPS data are limited and therefore the analysis is also limited. First, the no-stat properties we exclude are likely to have some number of long-term vacant properties in them, but since there is no way to distinguish vacant no-stats from others, we exclude no-stats, as mentioned. Second, as with most vacancy data, they are based on external conditions and the USPS employee's best judgement. Despite these 
limitations, USPS is considered to be one of the most reliable secondary vacancy datasets and the only one that measures the duration of vacancy of particular addresses (Perrin, 2016).

Starting from the entire universe of all tracts with USPS residential address data $(\mathrm{n}=$ 73,501 ), we eliminated tracts that did not fall within a metropolitan area, yielding 60,456 tracts. Then, we limited the study to the largest 200 metropolitan statistical areas (MSAs), because our interest is larger metros. However, limiting the analysis to too small a set of metros (e.g., largest 100 MSAs) would exclude metros of significant concern in the literature such as Youngstown, Ohio or Macon, Georgia. Limiting the study to the largest 200 metros reduced the number of tracts to 54,460. Between 2012 and 2019, a small number (38) of tracts had data recorded and reported for one year but not the other. Deleting these left us with 54,422 tracts in our dataset. While we look at patterns across all 200 metros, we focus especially on two important regions that were hit hard by the foreclosure crisis: the Rustbelt and the Sunbelt. To define the Sunbelt, we follow Strom (2017), where she includes the states that are partially or entirely south of the $37^{\text {th }}$ parallel, including North Carolina, South Carolina, Georgia, Alabama, Mississippi, Tennessee, Louisiana, Arkansas, Oklahoma, Texas, New Mexico, Arizona, Florida, and Nevada, and Southern California. For the Rustbelt, we use Hackworth's (2019) definition, which includes states adjacent to the Great Lakes: Indiana, Illinois, Michigan, Minnesota, New York, Ohio, Pennsylvania, and Wisconsin. His definition of Rustbelt also includes Louisville, Kentucky, and St. Louis, Missouri, since both metro's boundaries spill over into these states. However, we exclude the New York City and Philadelphia metropolitan areas, because their historical trajectories have been so distinct from other metros in these states. If a metro was partially in a Rustbelt- or Sunbelt-defined state, the entire metro was included in the study. The Sunbelt region is relatively larger, with 93 MSAs and 23,363 tracts, compared to the Rustbelt, which contains 
47 MSAs and 12,736 tracts. Figure 1 illustrates the locations of these MSAs, as well as the rest of the top 200 largest MSAs.

\section{[FIGURE 1 ABOUT HERE]}

We develop a typology utilizing six categories based on two key metropolitan characteristics: 1) the median home value, to distinguish low-versus high-cost metros; and 2) changes in housing prices and population over the recovery period. Median home value is commonly used in the construction of metropolitan market typologies in both academic and professional research and has been used for some time now (Joint Center for Housing Studies, 2017; Logan, 1976). To categorize metros by home value, we used the median home value for owner-occupied homes from the American Community Survey (ACS) at the MSA level for 2018. ${ }^{\mathrm{v}}$ After examining the distribution of home values at the metro level, $\$ 200,000$ was chosen as the cut-off point between low- and high-cost metros. This was slightly higher than the mean value at the metro level, but the data is substantially skewed, and this cut-off point corresponds to the top third of MSAs by the median value.

To categorize metros by post-recession growth and housing demand, we used two key variables: the Federal Housing Finance Agency (FHFA) Housing Price Index (HPI) change between 2011 and 2018 and the U.S. Census’ Population Estimate Program (PEP) from 2011 to 2018. ${ }^{\text {vi }}$ After calculating home price and population changes, we used the following rules to categorize MSAs into three distinct groups: low-growth MSAs, with a population change percentage below the average of all MSAs (4.59 percent), and an HPI change below the all-MSA average (27.58 percent); mixed-growth metros, which fell below the average on either population 
growth or housing price change, but not both; and high-growth metros, which were above the allMSA average for both variables.

\section{Changes in Tract Vacancy Levels from 2012 to 2019}

After examining the distributions of vacancy rates across census tracts, we define five levels of neighborhood vacancy: low, moderate, high, very high, and extreme. The "low" category includes all tracts that had a long-term vacancy rate of less than one percent. The "moderate" frequency includes all tracts with vacancies ranging from 1 to less than 4 percent. The "high" classification includes tracts with a rate of 4 to less than 8 percent. The "very high" category ranges from 8 percent to less than 14 percent, and the "extreme" category is any tract with a rate of 14 percent or higher. The cut-off points for these levels, much like the metropolitan typologies, were determined by examining the distribution of long-term vacancy rates at the census tract level.

Table 1 shows that 76 percent of all census tracts in the largest 200 metros fell into either the low or moderate categories in 2012 and 82.5 percent in 2019. A categorical approach allows us to focus on tracts with very high, or extreme levels of vacancy, which we group as "hypervacant," and how the numbers of such tracts changed over the 2012 to 2019 period. The top section of the table shows that for the 200 largest metros, the share of tracts that were hypervacant was just lightly under 10 percent (9.4 percent) and so represent approximately the top decile of vacancy. It also shows that the share of tracts that were hypervacant declined to 7.5 percent in 2019 .

\section{[TABLE 1 ABOUT HERE]}


Table 1 also shows that, in Sunbelt metros, the share of tracts that were hypervacant declined over the recovery period, dropping from 10.2 percent in 2012 to 6.6 percent in 2019 . There was also a substantial net shift from higher vacancy levels to the low level, with the latter increasing from 36.4 to 51.6 percent of all Sunbelt census tracts. Thus, while it appears that the greatest net reduction in vacancy occurred through a shift from moderate-to-high levels downward, there was also a substantial decline in hypervacant tracts.

The bottom row of Table 1 shows that, in Rustbelt metros, the share of tracts that were hypervacant did not decline substantially over the recovery period, with the share dropping only from 15.6 percent in 2012 to 15.4 percent in 2019 . It is noteworthy that the share of tracts in the Rustbelt that were hypervacant in 2019 was more than 50 percent higher than the comparable share in the Sunbelt at the beginning of the recovery in 2012. By the end of the study period, the share of tracts that were hypervacant was 2.3 times as large in the Rustbelt than in the Sunbelt. In the Rustbelt, the reduction in vacancy occurred almost entirely through a shift from moderate-tohigh levels downward, and not from the hypervacant categories. Hypervacancy appears to have been significantly more stubborn in the Rustbelt than in the Sunbelt.

\section{Changes in Tract Vacancy Levels by in Low-Cost, Low-Growth Metros}

In Table 1, it is clear that, overall, Rustbelt metros tend to have higher levels of hypervacancy than Sunbelt metros, and this hypervacancy dropped appreciably during the 2012 to 2019 period in the Sunbelt but not in the Rustbelt. But is there something that is particular to the Sunbelt as a spatial region that might explain this, or is it just that more of the Rustbelt 
metros are lower-cost and lower-growth areas than in the Sunbelt? To address this question, we analyze the vacancy trends in just the low-cost, low-growth metros in each of these regions.

While Rustbelt metros have not tended to grow as fast as Sunbelt metros during the recovery period, there are different types of metros in both regions. The Sunbelt region is especially heterogeneous. We break out the 200 largest metros into the six different metro types that we identified above. These categories include low-cost, low growth; low-cost, mixedgrowth; low-cost, high-growth; high-cost, low-growth; high-cost, mixed-growth; and high-cost, high-growth. Figure 2 indicates which categories the larger metros fall into in the Sunbelt and Rustbelt regions.

\section{[FIGURE 2 ABOUT HERE]}

As expected, lower-growth metros tend to be more common in the Rustbelt than in the Sunbelt. At the same time, neither region is homogeneous in this respect. There are some highgrowth metros in the Rustbelt, including Grand Rapids, Columbus, and Minneapolis.

Conversely, there are low-growth metros in the Sunbelt, including Birmingham, Memphis, and Jackson, among others.

Table 2 breaks out vacancy trends in low-cost, low-growth metros. This category includes 58 of the 200 largest MSAs, including 30 in the Rustbelt and 22 in the Sunbelt. Nationally, these metros showed less movement of neighborhoods to the lowest vacancy category compared to other metros, with small decreases at the moderate and high categories. There was little change in the share of hypervacant tracts. In low-cost, low-growth metros, the 
problems of hypervacancy persisted despite the national recovery. This occurred in such metros in both the Sunbelt and the Rustbelt.

\section{[TABLE 2 ABOUT HERE]}

While low-cost, low-growth metros are often assumed to be primarily located in the Rustbelt, only slightly over half of such MSAs are Rustbelt metros. These sorts of metros tend to exhibit substantial levels of hypervacancy regardless of the region of the country. However, a substantially larger share of Rustbelt metros fell into this category than was the case in the Sunbelt.

\section{The Racial and Economic Characteristics of Hypervacant Neighborhoods}

We next turn to the racial and poverty characteristics of neighborhoods at different vacancy levels in the Sunbelt and the Rustbelt, at the beginning and end of the study period. We are particularly interested in the characteristics of hypervacant tracts. Table 3 compares the racial compositions and poverty rates of tracts at different vacancy levels using the 2011 and 2018 fiveyear American Community Survey. The 2011 five-year ACS data are used to describe the Q1 2012 tracts and the 2018 five-year ACS data are used to describe the Q1 2019 tracts.

\section{[TABLE 3 ABOUT HERE]}

Low-vacancy tracts in the Rustbelt tend to have substantially lower Black and, especially, Latinx populations than low-vacancy tracts in the Sunbelt. ${ }^{\text {vii }}$ The poverty rates of low-vacancy tracts in the Sunbelt are also substantially higher. Over the recovery period, the mean percent 
Black and Latinx figures rose among low-vacancy tracts in both regions, as did the mean poverty rates.

Very high vacancy tracts tend to have substantially larger Black populations in the Rustbelt than in the Sunbelt, although that difference declined by 2019. In 2019, the very high vacancy tracts in the Sunbelt had increased from 31.7 percent Black to 35.5 percent Black, while declining from 42.3 percent to 38.5 percent Black in the Rustbelt. There was a large difference in Latinx shares between the regions, again due to the overall smaller Latinx population among Rustbelt metros. The poverty rates of very high vacancy tracts were high in 2019 , at 27.2 percent in Sunbelt and 29.6 percent in corresponding Rustbelt tracts.

Extreme vacancy tracts in both regions tended to have larger Black populations, with means ranging from 46.9 percent in the Sunbelt to 65.4 percent in the Rustbelt. While the mean percent of residents who are Black for such tracts increased in the Sunbelt, it declined significantly in the Rustbelt, although remained high, at 61.9 percent. The poverty rates of extreme vacancy tracts are high, and higher in the Rustbelt, with a mean of 31.0 percent in the Sunbelt and 38.2 percent in the Rustbelt. These figures held fairly steady over the recovery period.

Hypervacant tracts, whether in the Sunbelt or the Rustbelt, tend to have larger Black populations, although Rustbelt tracts in these categories have substantially larger Black percentages. It is also notable that, in the Rustbelt, the low and moderate-vacancy tracts have smaller Black populations. Overall, while the association between vacancy level and percentage Black is strong in both regions, it is stronger in the Rustbelt. This might be somewhat expected given the generally higher levels of Black segregation in the Rustbelt (Frey, 2018). 


\section{Estimating 2019 Hypervacancy}

Our next task is to estimate the likelihood of whether a census tract ends the 2012 to 2019 period as a hypervacant neighborhood. To do this we estimate a logistic regression of the form:

$$
\mathrm{Y}_{2019}=\log [\mathrm{p} /(1-\mathrm{p})]=\boldsymbol{\beta}_{0}+\boldsymbol{\beta}_{1} \mathbf{V}_{2012}+\boldsymbol{\beta}_{2} \mathbf{M}_{2012,2012-19}+\boldsymbol{\beta}_{3} \mathbf{N}_{2012}+\boldsymbol{\beta}_{3} \mathbf{R}+\mu
$$

where the binary dependent variable equals 1 when the tract is hypervacant in 2019 and 0 otherwise. $\mathbf{V}_{2012}$ is a set of dummy variables indicating the vacancy level of the tract in 2012, with the omitted reference variable being extreme vacancy, $\mathbf{M}_{2012,2012-19}$ is a set of metropolitanlevel variables indicating the economic and population levels and trends of the corresponding MSA, including population in 2011, population change from 2011 to 2018, unemployment rate in 2011, unemployment rate change from 2011 to 2018, median home value in 2011, and house price change from 2011 to 2018 . These are suggested by the literature, described above, on regional factors that affect housing vacancy. $\mathbf{N}_{2012}$ is a set of neighborhood-level characteristics including percent Black, percent Latinx, poverty rate, and other demographic and housing variables. The selection of these was informed by both the broader literature on neighborhood decline as well as the more specific literature that works to explain or predict neighborhood vacancy rates, both of which were discussed above. $\mathbf{R}$ is a set of two dummy variables indicating whether the tract is located in the Sunbelt, the Rustbelt, or neither region. These two variables are used to discern whether a neighborhood's location in the Rustbelt or Sunbelt has an independent association with hypervacancy, after controlling for metropolitan economic and growth factors. The model is run in three stages, first with just the initial vacancy level dummies $\left(\mathbf{V}_{2012}\right)$, then including all of the metro and neighborhood characteristics, and finally, including 
the regional dummies, R. Because the tracts come from 200 distinct metropolitan areas, robust standard errors clustered at the level of the MSA are used in estimating the regression.

Table 4 provides the descriptive statistics for the dependent and independent variables used in estimating equation 1 . Table 5 provides the results of estimating equation 1 as a logistic regression in three stages. The first stage (the first 3 columns) includes just the four dummy variables indicating which of the five initial vacancy levels the tract falls into in 2012 (extreme vacancy is the omitted, reference level). This is an initial-condition-only model, in which the likelihood of the tract being hypervacant in 2019 is a function of only the initial 2012 vacancy level of the tract. In the second stage, the metropolitan and neighborhood characteristics variables are added, including initial (2011) and change (2011-2018) metropolitan variables as well as the initial (2011) neighborhood characteristics as measured with ACS data. Finally, the third stage simply adds the two dummy variables indicating the region (Sunbelt, Rustbelt, or neither) in which the tract lies. This third stage is intended to test whether, after controlling for the initial vacancy level and metropolitan- and neighborhood-level variables, being located in the Rustbelt or the Sunbelt has an independent association with the odds of ending up as a hypervacant tract in 2019 .

[TABLE 4 ABOUT HERE]

[TABLE 5 ABOUT HERE]

The results in Table 5 show that, as expected, the initial vacancy level of the tract in 2012 is a strong predictor of whether a tract is hypervacant in 2019. The odds ratios for the dummy 
variables increase rapidly as the initial, 2011, vacancy rate moves from lower-to-higher vacancy levels.

The results in the second model, with the metropolitan- and neighborhood-level characteristics included, show an increase in the pseudo-R-squared from 0.5278 to 0.5872 and a large increase in the share of hypervacant tracts that are correctly classified by the regression. Because the overall share of hypervacant tracts in 2019 is modest, at less than 8 percent of all tracts, an important indicator of the performance of the model is how well it predicts that a tract will fall into the hypervacant category when it does, that is the share of hypervacant tracts that are correctly classified by the regression. In the second model, 62.5 percent of hypervacant tracts are correctly classified, compared to only 36.4 percent of hypervacant tracts in the initialconditions-only model. This suggests that knowing the metropolitan and neighborhood characteristics of a tract greatly improves the accuracy of the model in classifying whether it will be hypervacant in 2019 .

The third specification adds the two regional dummy variables (Sunbelt and Rustbelt). The changes in the results between these two specifications are quite modest, and the regional dummies are not statistically significant. This suggests that, after controlling for the neighborhood and metropolitan characteristics, as well as the initial vacancy level, whether a tract is in the Rustbelt or the Sunbelt is not a statistically significant predictor of hypervacancy in 2019. Thus, even though there are strong differences between the levels of hypervacancy in Sunbelt vs. Rustbelt metros, on average, the reason for this is largely explained by the metropolitan economic and growth conditions of the metros in the two regions. This finding is consistent with the earlier findings in Table 2, where low-cost, low-growth metros in both the Sunbelt and the Rustbelt exhibited similar vacancy patterns. 
Focusing on the full model, most of the coefficients come in with the expected signs. Tracts in larger metros, and growing metros, are associated with a lower likelihood of the tract being hypervacant in 2019 . Higher-cost metros, as measured by median home value, are also associated with a lower likelihood of hypervacancy in 2019; however, greater increases in home prices over the 2012 to 2019 period are not associated with the likelihood of hypervacancy. These results are all consistent with the results in Table 2, which suggested that hypervacancy is more stubborn in low-cost-low-growth metros.

In terms of neighborhood-level variables, the following 2011 characteristics are statistically significant: the proportion of residents who were Latinx, the poverty rate, the proportion of residents over age 65 , the proportion of adults who were college-educated, and the median year built of the housing stock. Higher Latinx shares are strongly and negatively associated with the likelihood of 2019 hypervacancy. Higher poverty rates and larger shares of elderly populations are strongly and positively associated with 2019 hypervacancy. Conversely, a higher share of the population that is college-educated is associated with a lower likelihood of hypervacancy in 2019. Newer neighborhoods, other things equal, are associated with a higher level of hypervacancy in 2019.

One finding that warrants some discussion is that the coefficient on the proportion Black (2011) while positive, is not statistically significant, even given this large sample size. (Multicollinearity was not an issue for this variable.) This contrasts with the bivariate results of Table 3. After controlling for poverty, median income, proportion over 65 , age of housing stock, and other variables, the share of residents who are Black is not significantly associated with hypervacancy. This does not contradict the strong association between Blackness and hypervacancy, however. This is because racial discrimination and racialized disinvestment 
contributed to the lower incomes and higher poverty, lower educational attainment, lower home values in Black neighborhoods. Moreover, Black neighborhoods tended to have a higher initial (2012) level of vacancy, which in turn is a strong predictor of hypervacancy in 2019.

\section{Conclusion}

The U.S. housing market recovery that began around 2012 brought with it increased housing demand and generally lower levels of housing vacancy. This recovery, however, was highly uneven, with population and home values growing much more in some regions than others. In this paper, we have focused on the change in hypervacant neighborhoods in larger metros over the 2012 to 2019 national recovery. It is in these neighborhoods where the cumulative negative impacts of vacancy, such as property values, crime, and health outcomes, are expected to be the most severe and where the problem of vacancy is likely to be the hardest to address.

Overall, we found that in the Sunbelt, the share of tracts that were hypervacant declined significantly over the 2012 to 2019 period. Meanwhile, in the Rustbelt metros, the share of hypervacant tracts remained roughly constant. Notably, the share of hypervacant tracts was still more than 50 percent higher in the Rustbelt in 2019 than in the Sunbelt in 2012, before the broader national recovery. Moreover, the hypervacant share in the Rustbelt was 2.3 times the Sunbelt share in 2019. The Rustbelt did see a net downward shift in vacancy, but it was primarily from tracts in the moderate and high levels shifting to the moderate or low levels while the share of tracts at the more extreme levels remained roughly constant.

Despite the greater persistence of hypervacant neighborhoods in the Rustbelt, the results show that hypervacant neighborhoods do exist in the Sunbelt to a significant degree. This is 
primarily because the Sunbelt also includes a substantial number of low-cost, low-growth metros, the type that tends to have the highest numbers of hypervacant tracts. Of the 58 larger metros in this category, 22 (38 percent) are located in the Sunbelt, while 30 (52 percent) are located in the Rustbelt. In both regions, these types of metros saw their shares of hypervacant tracts remain about constant over the 2012 to 2019 period, at about 17.5 percent, much higher than the overall share of less than 8 percent.

The results also show that hypervacancy is a phenomenon that is heavily racialized. Hypervacant tracts tended to have large Black and low-income populations, especially in Rustbelt metros. Conversely, low-vacancy tracts tended to have smaller Black populations, especially in the Rustbelt. Overall, the bivariate association between percentage Black and vacancy level was somewhat stronger in the Rustbelt than in Sunbelt metros.

The regression results demonstrate that the persistence of hypervacancy is shaped by the preexisting urban inequalities and intra-metropolitan disparities. At the neighborhood level, higher poverty rates and older and less-educated populations in 2012 are strongly associated with 2019 hypervacancy. Knowing these demographic relationships and knowing that larger Latinx populations and older housing stock, other things equal, are associated with lower 2019 hypervacancy, are important starting points for planners attempting to help communities mostly communities of color - address hypervacancy. With this knowledge, planners can help local governments target disinvestment mitigation interventions accordingly.

The regression results also suggest that, after controlling for metropolitan growth and economic factors, whether a city is located in the Sunbelt or the Rustbelt does not have an independent effect on hypervacancy. This is consistent with the fact that there are, in fact, weak- 
growth metros in both the Sunbelt and the Rustbelt, and that such metros in both regions tend to have high levels of vacancy and hypervacancy.

Despite being disproportionately present in Rustbelt cities, hypervacant neighborhoods can be present in different regions of the country, especially in metropolitan areas that are not growing and have low housing values. These neighborhoods are found in Birmingham and Memphis, as well as in Cleveland and Detroit. Therefore, the construction of a federal or state policy agenda that is aimed at assisting local governments in repurposing vacant properties to promote community development is needed. A key takeaway here is that such interventions should not just be thought of as Rustbelt policies but rather weak-market policies, even if the Rustbelt might disproportionately benefit from such efforts. This may also aid in building more political support at the federal level for such policies.

Finally, these findings have important implications for policy and practice in cities struggling with hypervacancy. Cities can pursue a variety of approaches to addressing hypervacancy, sometimes simultaneously. For example, one is to demolish vacant properties, especially those that are severely distressed. Another is to create, and ideally bring to scale, a public or quasi-public land banking system that acquires and maintains, or sometimes demolishes, vacant properties and facilitates their redevelopment (Alexander and Powell, 2011; Alexander, 2015). Through various means, cities may encourage adaptive reuse of vacant homes for a new purpose. Hackworth (2019) argues that focusing on large-scale demolition as part of urban "rightsizing" strategies resembles the misguided urban triage strategies of the 1970s. Despite the possible dangers of overly aggressive demolition programs, more targeted demolition efforts may have merit, especially if funding and detailed plans are in place to redevelop the parcels for socially beneficial uses such as affordable housing. Some studies find positive effects 
of demolition (Larson et. al., 2019; Paredes and Skidmore, 2017), while in others the results are more mixed (Griswold et al., 2014).

Housing vacancy, and especially hypervacancy, are likely to remain important issues facing urban scholars and policymakers, especially because Black and Latinx neighborhoods are more likely than white neighborhoods to be hypervacant. As national and metropolitan housing markets weaken, these problems are expected to worsen and, as is the case in this study, as metropolitan housing markets strengthen, hypervacancy tends to ebb. Hypervacant neighborhoods are also shaped significantly by neighborhood-level inequalities and disparities. Given the literature literature on historical segregation and housing discrimination processes, forces which we cannot directly measure here, such historical processes likely play an important role in current patterns of hypervacancy. Without stronger and reparative policy interventions, including the increased enforcement and expansion of the Fair Housing Act and the Community Reinvestment Act and greater public investment, these racialized patterns are likely to persist. Finally, while hypervacant neighborhoods are more likely to be located in the Rustbelt than in the Sunbelt, hypervacancy is not strictly a Rustbelt phenomenon. Sunbelt metros with weaker housing markets also tend to have roughly the same levels of vacancy and hypervacancy as weak-market Rustbelt metros. This fact is important for reframing the problem of hypervacancy as one not solely affecting the Rustbelt. 


\section{REFERENCES}

Accordino, J., \& Johnson, G. T. (2000). Addressing the vacant and abandoned property problem. Journal of Urban Affairs, 22(3), 301-315.

Alexander, F. S., \& Powell, L. A. (2011). Neighborhood stabilization strategies for vacant and abandoned properties. Zoning and Planning Law Report, 34(8), 11-179.

Alexander, F. S. (2015). Land banks and land banking: $2^{\text {nd }}$ Edition. Flint, MI: Center for Community Progress.

Bradbury, K., Downs, K., and Small, K. (1982). Urban decline and the future of American cities. Washington, DC: Brookings Institution.

Branas, C. C., Rubin, D., \& Guo, W. (2012). Vacant properties and violence in neighborhoods. ISRN Public Health.

Cohen, J. (2001). Abandoned housing: Exploring lessons from Baltimore. Housing Policy Debate 12: 415-448.

Cui, L., \& Walsh, R. (2015). Foreclosure, vacancy and crime. Journal of Urban Economics, 87, 72-84.

Dreier, P., Mollenkopf, J., and Swanstrom, T. 2014. Place matters: Metropolitics for the twentyfirst century. Lawrence, KS: University Press of Kansas.

Frey, W. (2018). Black-white segregation edges downward since 2000, Census shows. Brookings Institution. December 17. https://www.brookings.edu/blog/theavenue/2018/12/17/black-white-segregation-edges-downward-since-2000-census-shows/.

Galster, G. 2012. Driving Detroit: The quest for respect in the motor city. Philadelphia: University of Pennsylvania Press.

Glaeser, E. and Gyourko, J. (2005). Urban decline and durable housing. Journal of Political Economy. 113: 345-375.

Goetz, E. G., Cooper, K., Thiele, B., \& Lam, H. (1998). Pay now or pay more later: St. Paul's experience in rehabilitating vacant housing. CURA Reporter, 14.

Grigsby, W., Baratz, M., Galster, G., and MacLennan, D. (1987). The dynamics of neighborhood change and decline. Progress in Planning 28: 1-76.

Griswold, N., Calnin, B., Schramm, M., Anselin, L., \& Boehnlein, P. (2014). Estimating the effect of demolishing distressed structures in Cleveland, OH, 2009-2013: Impacts on real estate equity and mortgage-foreclosure. Griswold Consulting Group. 
Hackworth, J. (2019). Manufacturing decline: How racism and the conservative movement crush the American Rust Belt. Columbia University Press.

Han, H. S. (2014). The impact of abandoned properties on nearby property values. Housing Policy Debate, 24(2), 311-334.

Hillier, A., Culhane, D., Smith, T., and Tomlin, C. 2003. Predicting housing abandonment with the Philadelphia Neighborhood Information System. Journal of Urban Affairs 25: 91105.

Hollander, J. B. (2011). Sunburnt cities: The great recession, depopulation and urban planning in the American sunbelt. Routledge.

Immergluck, D. (2009a). Foreclosed: High-risk lending, deregulation, and the undermining of America's mortgage market. Cornell University Press.

Immergluck, D. (2009b). The foreclosure crisis, foreclosed properties, and federal policy: Some implications for housing and community development planning. Journal of the American Planning Association, 75(4), 406-423.

Immergluck, D. (2015). Preventing the next mortgage crisis: The meltdown, the federal response, and the future of housing in America. Baltimore: Rowman and Littlefield.

Immergluck, D. (2016). Examining changes in long-term neighborhood housing vacancy during the 2011 to 2014 US national recovery. Journal of Urban Affairs, 38(5), 607-622

Joint Center for Housing Studies of Harvard University. (2017). The State of the Nation's Housing 2017. Accessed at https://www.jchs.harvard.edu/sites/default/files/reports/files/harvard_jchs_state_of_the_n ations_housing_2017.pdf

Kerner Commission Report. 1968. U.S. National Advisory Commission on Civil Disorders. Washington, DC: U.S. Government Printing Office.

Korver-Glenn, E. (2018). Compounding inequalities: How racial stereotypes and discrimination accumulate across the stages of housing exchange. American Sociological Review 83: 627-656.

Larson, M., Xu, Y., Ouellet, L., \& Klahm IV, C. F. (2019). Exploring the impact of 9398 demolitions on neighborhood-level crime in Detroit, Michigan. Journal of Criminal Justice, 60, 57-63.

Logan, J. R. (1976). Industrialization and the stratification of cities in suburban regions. American Journal of Sociology, 82(2), 333-348. 
Mallach, A. (2006). Bringing buildings back: From abandoned properties to community assets. New Brunswick: Rutgers University Press.

Mallach, A. (2018a). The empty house next door: Understanding and reducing vacancy and hypervacancy in the United States. https://www.lincolninst.edu/sites/default/files/pubfiles/empty-house-next-door-full.pdf.

Mallach, A. (2018b). Divided cities: Poverty and prosperity in urban America. Island Press.

Molloy, R., 2016. Long-term vacant housing in the United States. Regional Science and Urban Economics, 59, pp.118-129.

Morckel, V. (2013) Empty neighborhoods: Using constructs to predict the probability of housing abandonment. Housing Policy Debate, 23:3, 469-496.

Moyer, R., MacDonald, J. M., Ridgeway, G., \& Branas, C. C. (2019). Effect of remediating blighted vacant land on shootings: a citywide cluster randomized trial. American Journal of Public Health, 109(1), 140-144.

Newman, G., Gu, D., Kim, J. H., \& Li, W. (2016). Elasticity and urban vacancy: A longitudinal comparison of US cities. Cities, 58, 143-151.

Paredes, D., \& Skidmore, M. (2017). The net benefit of demolishing dilapidated housing: The case of Detroit. Regional Science and Urban Economics, 66, 16-27.

Pendall, R., Martin, S., Astone, N., Nichols, A., Franks, K., Stolte, A., and Peters, E. 2015. Scenarios for Regional Growth from 2010 to 2030. Urban Institute. January 20. https://www.urban.org/research/publication/scenarios-regional-growth-20102030/view/full_report.

Perrin, G. (2016). Report on Detroit Land Bank Authority Occupancy Model. New York University. Retrieved from https://www.authorea.com/users/106318/articles/138757report-on-detroit-land-bank-aut hority-occupancy-model/_show_article\#

Raleigh, E., \& Galster, G. (2015). Neighborhood disinvestment, abandonment, and crime dynamics. Journal of Urban Affairs, 37(4), 367-396.

Sampson, N., Nassauer, J., Schulz, A., Hurd, K., Dorman, C., \& Ligon, K. (2017). Landscape care of urban vacant properties and implications for health and safety: Lessons from Photovoice. Health \& Place, 46, 219-228.

Satter, B. (2010). Family properties: How the struggle over race and real estate transformed Chicago and urban America. New York: Picador. 
Schilling, J., \& Logan, J. (2008). Greening the rust belt: A green infrastructure model for right sizing America's shrinking cities. Journal of the American Planning Association 74: 451466.

Shin, E. K., \& Shaban-Nejad, A. (2018). Urban Decay and Pediatric Asthma Prevalence in Memphis, Tennessee: Urban Data Integration for Efficient Population Health Surveillance. IEEE Access, 6, 46281-46289.

Sternlieb, G., Burchell, R. W., Hughes, J. W., \& James, F. J. (1974). Housing abandonment in the urban core. Journal of the American Institute of Planners 40: 321-332.

Strom, E. (2017). How place matters: A view from the Sunbelt. Urban Affairs Review, 53(1), 197-209.

Taylor, K. 2019. Race for profit: How banks and the real estate industry undermined black homeownership. University of North Carolina Press.

U.S. Department of Housing and Urban Development. (2018). USPS Vacancy Data: Frequently Asked Questions. https://www.huduser.gov/portal/datasets/usps/FAQ_2012.pdf

Wang, K., \& Immergluck, D. (2018). The geography of vacant housing and neighborhood health disparities after the US foreclosure crisis. Cityscape, 20(2), 145-170.

Wang, K. and Immergluck, D., (2019). Housing vacancy and urban growth: explaining changes in long-term vacancy after the US foreclosure crisis. Journal of Housing and the Built Environment, 34(2), pp.511-532.

Whitaker, S., \& Fitzpatrick IV, T. J. (2013). Deconstructing distressed-property spillovers: The effects of vacant, tax-delinquent, and foreclosed properties in housing submarkets. Journal of Housing Economics, 22(2), 79-91. 
Table 1. Census Tracts by Vacancy Level, 2012 and 2019, 200 Largest MSAs

\begin{tabular}{|c|c|c|c|c|c|c|}
\hline & Year (Quarter) & Low & Moderate & High & Very High & Extreme \\
\cline { 2 - 7 } $\begin{array}{c}\text { All } \\
\text { ( } \mathrm{n}=200 \text { MSAs }\end{array}$ & $\mathbf{2 0 1 2}$ (Q1) & $\begin{array}{c}19,632 \\
(36.07 \%)\end{array}$ & $\begin{array}{c}21,747 \\
(39.98 \%)\end{array}$ & $\begin{array}{c}7,896 \\
(14.51 \%)\end{array}$ & $\begin{array}{c}3,367 \\
(6.19 \%)\end{array}$ & $\begin{array}{c}1,770 \\
(3.25 \%)\end{array}$ \\
\cline { 2 - 7 }$\& 54,422$ tracts) & $\mathbf{2 0 1 9}$ (Q1) & $\begin{array}{c}26,764 \\
(49.18 \%)\end{array}$ & $\begin{array}{c}18,115 \\
(33.29 \%)\end{array}$ & $\begin{array}{c}5,438 \\
(9.99 \%)\end{array}$ & $\begin{array}{c}2,511 \\
(4.61 \%)\end{array}$ & $\begin{array}{c}1,594 \\
(2.93 \%)\end{array}$ \\
\hline
\end{tabular}

\begin{tabular}{|c|c|c|c|c|c|c|}
\hline \multirow{3}{*}{$\begin{array}{c}\text { Sunbelt } \\
(n=93 \text { MSAs } \\
\& 23,363 \text { tracts })\end{array}$} & Year (Quarter) & Low & Moderate & High & Very High & Extreme \\
\hline & 2012 (Q1) & $\begin{array}{c}8,513 \\
(36.44 \%)\end{array}$ & $\begin{array}{c}8,537 \\
(36.54 \%)\end{array}$ & $\begin{array}{c}3,939 \\
(16.86 \%)\end{array}$ & $\begin{array}{c}1,731 \\
(7.41 \%)\end{array}$ & $\begin{array}{c}643 \\
(2.75 \%)\end{array}$ \\
\hline & 2019 (Q1) & $\begin{array}{c}12,060 \\
(51.62 \%)\end{array}$ & $\begin{array}{c}7,222 \\
(30.91 \%)\end{array}$ & $\begin{array}{c}2,548 \\
(10.91 \%)\end{array}$ & $\begin{array}{c}1,060 \\
(4.54 \%)\end{array}$ & $\begin{array}{c}473 \\
(2.02 \%)\end{array}$ \\
\hline
\end{tabular}

\begin{tabular}{|c|c|c|c|c|c|c|}
\hline \multirow{3}{*}{$\begin{array}{c}\text { Rustbelt } \\
(n=47 \mathrm{MSAs} \\
\& 12,736 \text { tracts })\end{array}$} & Year (Quarter) & Low & Moderate & High & Very High & Extreme \\
\hline & 2012 (Q1) & $\begin{array}{c}3,302 \\
(25.93 \%)\end{array}$ & $\begin{array}{c}5,289 \\
(41.53 \%)\end{array}$ & $\begin{array}{c}2,159 \\
(16.95 \%)\end{array}$ & $\begin{array}{l}1,080 \\
(8.48 \%)\end{array}$ & $\begin{array}{c}906 \\
(7.11 \%)\end{array}$ \\
\hline & 2019 (Q1) & $\begin{array}{c}4,256 \\
(33.42 \%)\end{array}$ & $\begin{array}{c}4,811 \\
(37.77 \%)\end{array}$ & $\begin{array}{c}1,711 \\
(13.43 \%)\end{array}$ & $\begin{array}{c}1,024 \\
(8.04 \%)\end{array}$ & $\begin{array}{c}934 \\
(7.33 \%)\end{array}$ \\
\hline
\end{tabular}


Table 2. Low-Cost, Low-Growth MSAs: Census Tracts by Vacancy Level, 2012 - 2019

\begin{tabular}{|c|c|c|c|c|c|c|}
\hline & Year (Quarter) & Low & Moderate & High & Very High & Extreme \\
\cline { 2 - 6 } $\begin{array}{c}\text { All } \\
(n=58 \text { MSAs }\end{array}$ & $\mathbf{2 0 1 2}(\mathbf{Q 1})$ & $\begin{array}{c}2,454 \\
(28.08 \%)\end{array}$ & $\begin{array}{c}3,122 \\
(35.72 \%)\end{array}$ & $\begin{array}{c}1,655 \\
(18.94 \%)\end{array}$ & $\begin{array}{c}883 \\
(10.10 \%)\end{array}$ & $\begin{array}{c}626 \\
(7.16 \%)\end{array}$ \\
\cline { 2 - 7 }$\& 8,740$ tracts) & $\mathbf{2 0 1 9}(\mathbf{Q 1 )}$ & $\begin{array}{c}2,988 \\
(34.19 \%)\end{array}$ & $\begin{array}{c}2,821 \\
(32.28 \%)\end{array}$ & $\begin{array}{c}1,398 \\
(16.00 \%)\end{array}$ & $\begin{array}{c}891 \\
(10.19 \%)\end{array}$ & $\begin{array}{c}642 \\
(7.35 \%)\end{array}$ \\
\hline
\end{tabular}

\begin{tabular}{|c|c|c|c|c|c|c|}
\hline & Year (Quarter) & Low & Moderate & High & Very High & Extreme \\
\cline { 2 - 6 } & $\mathbf{2 0 1 2}$ (Q1) & $\begin{array}{c}951 \\
\text { Sunbelt } \\
(n=22 \text { MSAs }\end{array}$ & $\begin{array}{c}793 \\
(29.39 \%)\end{array}$ & $\begin{array}{c}466 \\
(17.34 \%)\end{array}$ & $\begin{array}{c}280 \\
(10.42 \%)\end{array}$ & $\begin{array}{c}197 \\
(7.33 \%)\end{array}$ \\
\cline { 2 - 6 }$\& 2,687$ tracts) & $\mathbf{2 0 1 9}$ (Q1) & $\begin{array}{c}1,074 \\
(39.97 \%)\end{array}$ & $\begin{array}{c}731 \\
(27.21 \%)\end{array}$ & $\begin{array}{c}412 \\
(15.33 \%)\end{array}$ & $\begin{array}{c}262 \\
(9.75 \%)\end{array}$ & $\begin{array}{c}208 \\
(7.74 \%)\end{array}$ \\
\hline
\end{tabular}

\begin{tabular}{|c|c|c|c|c|c|c|}
\hline \multirow{3}{*}{$\begin{array}{c}\text { Rustbelt } \\
(n=30 \mathrm{MSAs} \\
\& 5,595 \text { tracts })\end{array}$} & Year (Quarter) & Low & Moderate & High & Very High & Extreme \\
\hline & 2012 (Q1) & $\begin{array}{c}1,344 \\
(24.02 \%)\end{array}$ & $\begin{array}{c}2,187 \\
(39.09 \%)\end{array}$ & $\begin{array}{c}1,088 \\
(19.45 \%)\end{array}$ & $\begin{array}{c}560 \\
(10.01 \%)\end{array}$ & $\begin{array}{c}416 \\
(7.44 \%)\end{array}$ \\
\hline & 2019 (Q1) & $\begin{array}{c}1,755 \\
(31.37 \%)\end{array}$ & $\begin{array}{c}1,958 \\
(35.00 \%)\end{array}$ & $\begin{array}{c}893 \\
(15.96 \%)\end{array}$ & $\begin{array}{c}574 \\
(10.26 \%)\end{array}$ & $\begin{array}{c}415 \\
(7.42 \%)\end{array}$ \\
\hline
\end{tabular}


Table 3. Mean Racial, Ethnic and Poverty Characteristics of Tracts by Vacancy Level

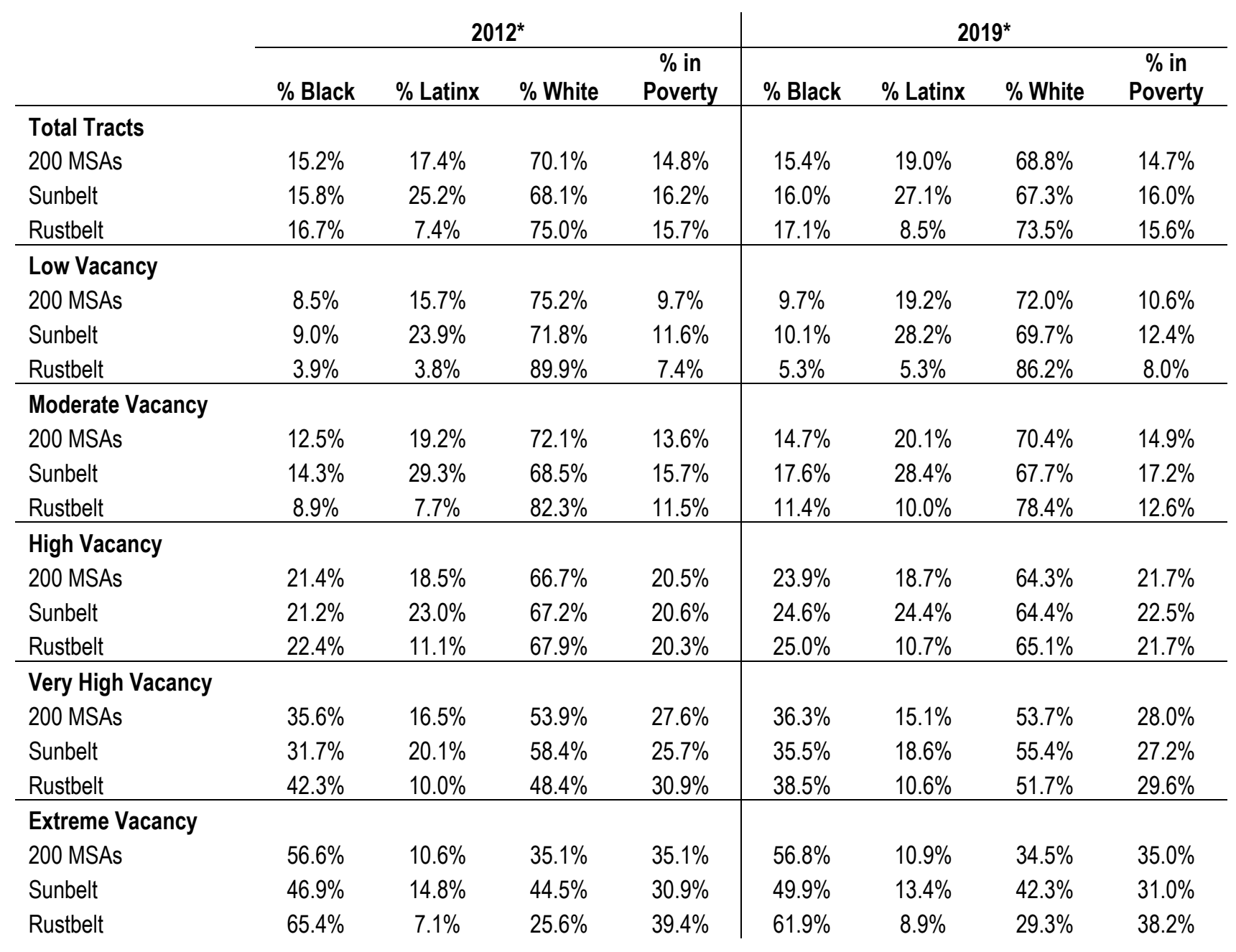

*Note: 2012 demographic characteristics are calculated using 2011 5-year ACS data; 2019 demographic characteristics are calculated using 2018 5-year ACS data. 
Table 4. Descriptive statistics

\begin{tabular}{lrc} 
& Mean & Std. Deviation \\
\hline Hypervacant 2019 (8\% or more vacant) & 0.0740 & 0.2618 \\
Low Vacancy 2012 (0 to 0.99\% vacant) & 0.3553 & 0.4786 \\
Moderate Vacancy 2012 (1 to 3.99\% vacant) & 0.4047 & 0.4908 \\
High Vacancy 2012 (4 to 7.99\% vacant) & 0.1465 & 0.3536 \\
Very High Vacancy 2012 (8 to 13.99\% vacant) & 0.0621 & 0.2414 \\
MSA Population 2011 & $4,648,852$ & $5,386,979$ \\
MSA Population Change 2011 - 2018 & 0.0590 & 0.0551 \\
MSA Unemployment Rate 2011 & 0.0895 & 0.0190 \\
MSA Change in Unemployment Rate 2011-2018 & -0.0508 & 0.0159 \\
MSA Housing Price Index Change, 2011-2018 & 0.3845 & 0.2603 \\
MSA Median Home Value 2018 & 278,268 & 154,845 \\
Proportion Black 2011 & 0.1500 & 0.2327 \\
Proportion Latinx 2011 & 0.1746 & 0.2235 \\
Median Housing Income 2011 & 60,443 & 29,710 \\
Owner-occupancy rate 2011 & 0.6352 & 0.2418 \\
Poverty rate 2011 & 0.1474 & 0.1271 \\
Proportion over 65 2011 & 0.1279 & 0.0762 \\
Proportion college-educated 2011 & 0.3087 & 0.2037 \\
Proportion commuting over 30 minutes 2011 & 0.3734 & 0.1632 \\
Median Year Built 2011 & 1970 & 18 \\
Sunbelt & 0.4282 & 0.4948 \\
Rustbelt & 0.2344 & 0.4236 \\
N = 53,424 & & \\
\end{tabular}




\section{Table 5. Logistic Regression}

Dependent Variable $=$ Tract is hypervacant in $2019=1$; tract is not hypervacant $=0$

Standard errors are robust and clustered at the level of the MSA

\begin{tabular}{|c|c|c|c|c|c|c|c|c|c|c|c|}
\hline & $\begin{array}{l}\text { Odds } \\
\text { Ratio }\end{array}$ & $\mathbf{z}$ & Sig & Odds Ratio & $\mathbf{z}$ & Sig & & Odds Ratio & $\mathbf{z}$ & Sig & \\
\hline Constant & 5.4364 & 9.43 & $0.000^{k * *}$ & 3.17E+18 & 5.81 & 0.000 & $* * *$ & $9.44 \mathrm{E}+19$ & 6.1 & 0.000 & $* * *$ \\
\hline Low Vacancy 2012 & 0.0006 & -34.74 & $0.000^{k * *}$ & 0.0014 & -20.82 & 0.000 & $* * *$ & 0.0014 & -20.75 & 0.000 & $* * *$ \\
\hline Moderate Vacancy 2012 & 0.0012 & -36.63 & $0.000^{* * *}$ & 0.0028 & -36.45 & 0.000 & $* * *$ & 0.0029 & -36.01 & 0.000 & $* * *$ \\
\hline High Vacancy 2012 & 0.0199 & -24.63 & $0.000^{* * *}$ & 0.0271 & -31.80 & 0.000 & $* * *$ & 0.0273 & -31.72 & 0.000 & *** \\
\hline Very High Vacancy 2012 & 0.1747 & -13.18 & $0.000 * * *$ & 0.2009 & -16.95 & 0.000 & $* * *$ & 0.2007 & -16.77 & 0.000 & $* * *$ \\
\hline MSA Population 2011 & & & & 0.999999 & -3.33 & 0.001 & $* * *$ & 0.999999 & -3.38 & 0.001 & *** \\
\hline MSA Population Change 2011-18 & & & & 0.0012 & -3.69 & 0.000 & *** & 0.0008 & -3.61 & 0.000 & *** \\
\hline MSA Unemployment Rate 2011 & & & & 3.3536 & 0.13 & 0.893 & & 2.1655 & 0.09 & 0.932 & \\
\hline MSA Change in Unemployment Rate 2011-18 & & & & 0.6277 & -0.04 & 0.965 & & 0.7972 & -0.02 & 0.983 & \\
\hline MSA Median Home Value 2011 & & & & 0.999998 & -2.70 & 0.007 & *** & 0.999998 & -2.01 & 0.044 & ** \\
\hline MSA House Price Index Change, 2011-18 & & & & 1.2234 & 0.48 & 0.628 & & 1.1624 & 0.36 & 0.717 & \\
\hline Proportion Black 2011 & & & & 1.4318 & 1.57 & 0.117 & & 1.3749 & 1.34 & 0.181 & \\
\hline Proportion Latinx 2011 & & & & 0.3920 & -2.93 & 0.003 & $* * *$ & 0.3691 & -3.1 & 0.002 & $* * *$ \\
\hline Median Housing Income 2011 & & & & 0.999993 & -1.45 & 0.148 & & 0.999993 & -1.38 & 0.168 & \\
\hline Owner-occupancy rate 2011 & & & & 1.4370 & 1.07 & 0.286 & & 1.3978 & 0.97 & 0.331 & \\
\hline Poverty rate 2011 & & & & 5.3295 & 4.21 & 0.000 & $* * *$ & 5.3594 & 4.23 & 0.000 & *** \\
\hline Proportion over 652011 & & & & 5.4949 & 2.90 & 0.004 & $* * *$ & 5.1435 & 2.82 & 0.005 & $* * *$ \\
\hline Proportion college-educated 2011 & & & & 0.2515 & -8.06 & 0.000 & $* * *$ & 0.2411 & -8.48 & 0.000 & $* * *$ \\
\hline Proportion commuting > 30 minutes 2011 & & & & 1.2913 & 0.64 & 0.522 & & 1.3424 & 0.73 & 0.465 & \\
\hline Median Year Built 2011 & & & & 0.9795 & -5.44 & 0.000 & $* * *$ & 0.9777 & -5.85 & 0.000 & *** \\
\hline Sunbelt & & & & & & & & 1.3440 & 1.39 & 0.165 & \\
\hline Rustbelt & & & & & & & & 1.1933 & 0.68 & 0.494 & \\
\hline \multicolumn{12}{|l|}{$N=53,424$} \\
\hline Pseudo R-square & 0.5278 & & & 0.5872 & & & & 0.5876 & & & \\
\hline$\%$ of all observations classified correctly & $94.7 \%$ & & & $95.8 \%$ & & & & $95.8 \%$ & & & \\
\hline$\%$ of actual hypervacant classified correctly & $36.4 \%$ & & & $62.5 \%$ & & & & $62.4 \%$ & & & \\
\hline
\end{tabular}


Figure 1. 200 Largest Metros

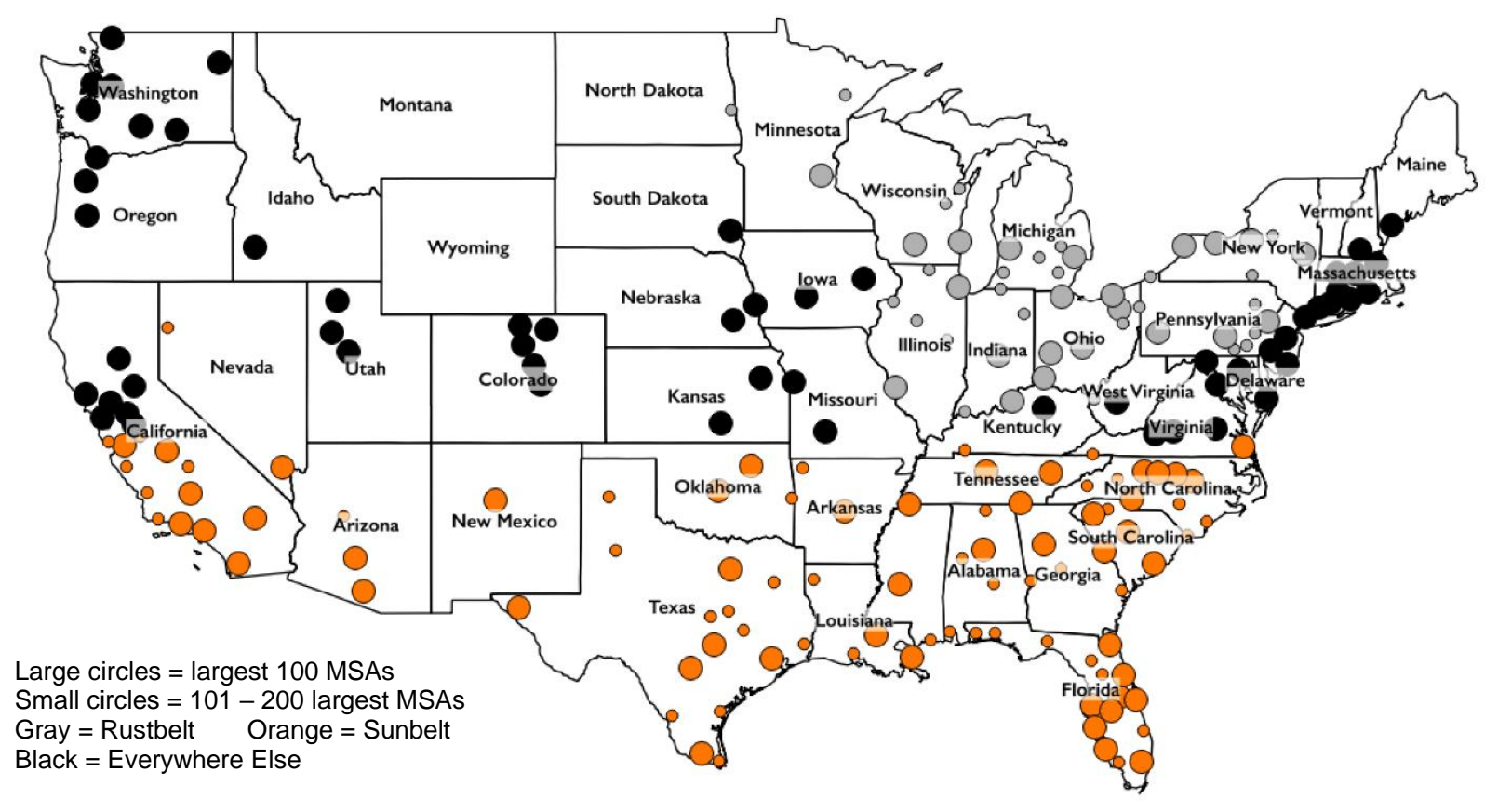


Figure 2. Large Sunbelt and Rustbelt Metros by Cost and Growth Type

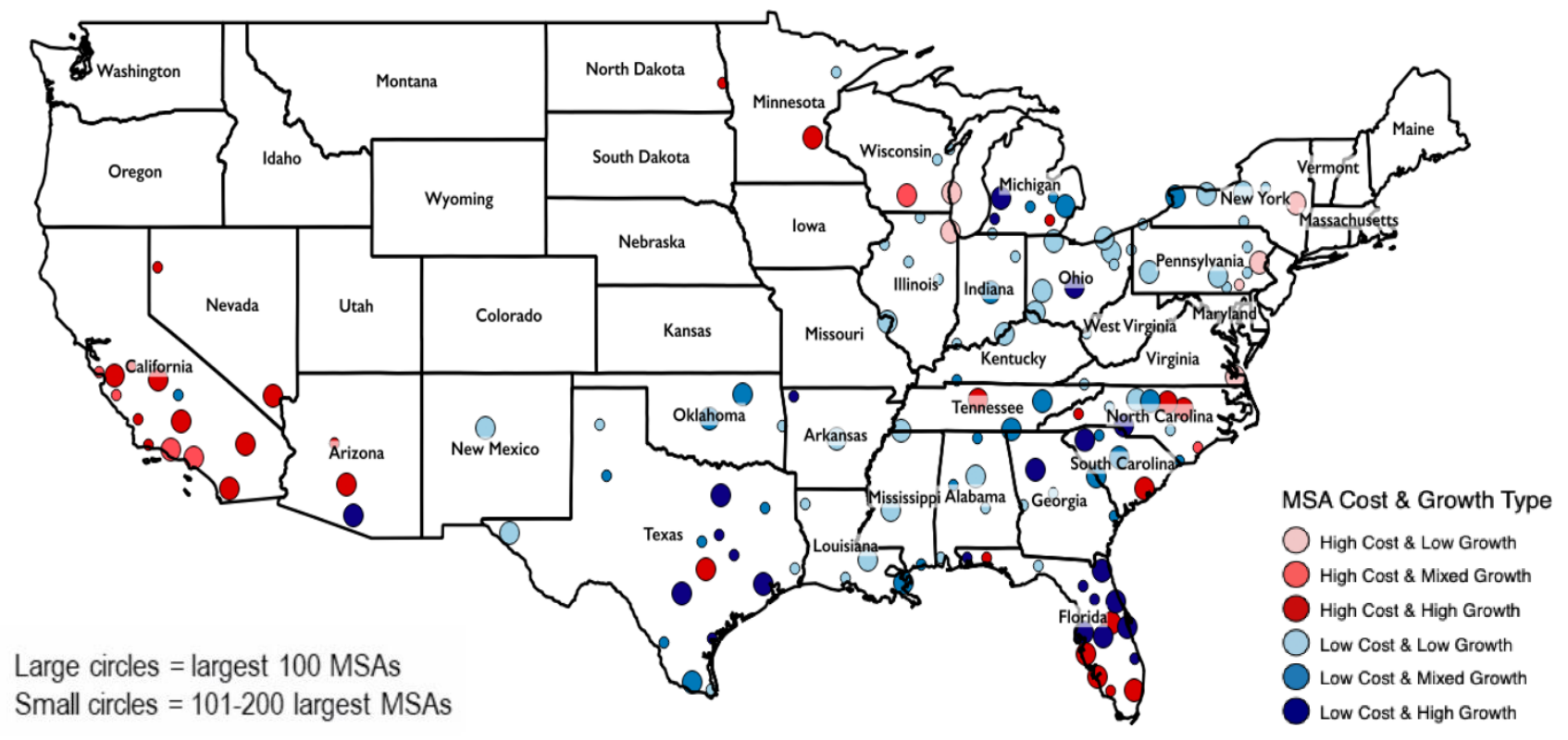


Notes

i The Rustbelt is defined here as it is by Hackworth (2019), who includes the states bordering the Great Lakes including Indiana, Illinois, Michigan, Minnesota, New York, Ohio, Pennsylvania, and Wisconsin, as well as two large metropolitan areas that spill over into these states: St. Louis and Louisville. Two metropolitan areas in these states are not included in the Rustbelt: the New York City and Philadelphia metros. These two very large metros are quite distinct from most Rustbelt metros, in that they are national and international-level "first-tier" metros that were never primarily dominated by the industrial history and decline facing most Rustbelt metros. The Sunbelt is defined as it has been by Strom (2017), which includes the states south of the 37th parallel: North Carolina, South Carolina, Georgia, Alabama, Mississippi, Tennessee, Louisiana, Arkansas, Oklahoma, Texas, New Mexico, Arizona, Florida, Nevada, and Southern California.

ii Morckel (2013) also uses population change at the tract level, but this variable is problematic because it may be as much the outcome of housing vacancy as the cause of it, especially at the neighborhood level. (Below, we do include a population change variable, but only at the metropolitan level).

iii We explored the use of cluster analysis, but the results but the separation of the clusters was not strong, and the resulting groups did not always make intuitive sense.

${ }^{\text {iv }}$ In the third quarter data release of 2011, there was significant change in methodology and reporting, making it problematic to compare data before and after Q3 2011. The data also began to be reported in 2010 census tracts in 2012, eliminating the need to estimate changes across differing census geographies. 
${ }^{v}$ The median home value figures were from the 2018 5-year American Community Survey estimates.

${ }^{\text {vi }}$ From 2011 to 2018, delineations of MSAs by the U.S. Office of Management and Budget (OMB) changed. Therefore, we manually cross-walked the 2011 data using the 2018 definition and county data to create spatially comparable 2011 data for calculation of the change variable. The MSA definitions are based on the 2018 OMB definition.

${ }^{\text {vii }}$ Rustbelt metros tend to have substantially smaller Latinx populations than Sunbelt metros. Of all tracts among the 200 largest metros, the mean Latinx share was $27.9 \%$ in 2018 in the Sunbelt versus $8.5 \%$ in the Rustbelt. 